1 Fraser IS. Contraceptive choices for women with "risk factors". Drug Safety 1993;8:271-9.

2 Vessey M, Mant D, Smith A. Oral contraceptives and venous thromboembolism. BrMed F 1986;292:526.

3 Abdalla $M$, Mostafa E. Contraception after heart surgery. Contraception 1992;45:73-80.

4 Bodgers J, Huikeshoven F, Lotgering F. Complications of anticoagulant therapy in ovulatory women. Lancet 1991; anticoagulant

5 Comp PC, Zacur HA. Contraceptive choices in women with coagulation disorders. Am f Obstet Gynecol 1993; 168:1990-3.

6 Turpie A, Gent M, Laupacis A, Latour Y, Gunstensen J, Basile F, et al. A comparison of aspirin with placebo in patients treated with warfarin after heart valve replacement. N Engl F Med 1993;329:524-9.

7 Fihn SD, McDonell M, Martin D, Henikoff J, Fihn SD, McDonell M, Martin D, Henikoff J,
Vermes D, Kent D, et al. Risk factors for complications of chronic anticoagulation. Ann Intern Med 1993;118: of chron.

\title{
ABSTRACTS IN CARDIOLOGY
}

\section{Atherosclerosis of the aortic arch and the risk of ischaemic stroke}

Atherosclerotic disease of the thoracic aorta is a potential source of cerebral embolism. Amarenco et al found a strong independent association between atherosclerotic disease of the aortic arch and the risk of ischaemic stroke. Few reports have focused on the ascending thoracic aorta as a potential source of embolic strokes and such evidence is needed before the thoracic aorta is included in the routine transoesophageal (TOE) assessment of heart patients with embolic stroke. TOE could in some cases alert surgeons to be vigilant during aortic clamping to avoid perioperative thromboembolism. This advantage may be more relevant to coronary angiography, however, as it might be better to use the right brachial artery cut-down technique (Sones) rather than the femoral artery route (Judkin) to reduce the risk of the catheter dislodging plaque in patients shown by TOE to be at high risk before catheterisation.

The retrospective detection of thick plaques by TOE unfortunately does not contribute to patient care and if it has no influence on management it is questionable whether the mild discomfort and cost of TOE in all patients with embolic stroke can be justified. It is more reasonable to regard atherosclerotic plaques detected by TOE or by any other means simply as evidence of diffuse atheromatosis and, as with coronary or peripheral vascular disease, to treat patients with antiplatelet agents, especially if they are over the age of 60 .

PETROS NIHOYANNOPOULOS

\section{Atherosclerotic disease of the aortic arch and the risk of ischemic stroke}

Pierre Amarenco, Ariel Cohen, Christophe Tzourio, Bernard Bertrand, Marc Hommel, Gérard Besson, Christophe Chauvel, Pierre-fean Touboul, Marie-Germaine Bousser

\section{Abstract}

Background-Atherosclerotic disease of the aortic arch has been suspected to be a potential source of cerebral emboli. We conducted a study to quantify the risk of ischemic stroke associated with atherosclerotic disease of the aortic arch.

Methods-Using transesophageal echocardiography, we performed a prospective case-control study of the frequency and thickness of atherosclerotic plaques in the ascending aorta and proximal arch in 250 consecutive patients admitted to the hospital with ischemic stroke and 250 consecutive controls, all over the age of 60 years.

Results-Atherosclerotic plaques $\geqslant 4 \mathrm{~mm}$ in thickness were found in 14.4 percent of the patients but in only 2 percent of the controls. After adjustment for atherosclerotic risk factors, the odds ratio for ischemic stroke among patients with such plaques was $9 \cdot 1$ (95 percent confidence interval, 3.3 to $25.2 ; P<0.001$ ). Among the 78 patients who had brain infarcts with no obvious cause, $28 \cdot 2$ percent had plaques $\geqslant 4 \mathrm{~mm}$ in thickness, as compared with $8 \cdot 1$ percent of the 172 patients who had infarcts whose possible or likely causes were known (odds ratio, 4.7; 95 percent confidence interval, 2.2 to $10.1 ; P<0.001$ ). Plaques of $\geqslant 4 \mathrm{~mm}$ in the aortic arch were not associated with the presence of atrial fibrillation or stenosis of the extracranial internal carotid artery. In contrast, plaques that were 1 to $3.9 \mathrm{~mm}$ thick were frequently associated with carotid stenosis of $\geqslant 70$ percent.

Conclusions-These results indicate a strong, independent association between atherosclerotic disease of the aortic arch and the risk of ischemic stroke. The association was particularly strong with thick plaques. Atherosclerotic disease of the aortic arch should be regarded as a risk factor for ischemic stroke and as a possible source of cerebral emboli. ( $N$ Engl f Med 1994;331:1474-9). 